\title{
Reseach article \\ Association of neck circumference with prehypertension and obesity in young paramedical students
}

\author{
Shanmugarajah Mangani Mangalavalli ${ }^{1}$, Senthamil Selvi Kaliyaperumal ${ }^{1}$, Velusami Deepika ${ }^{2}$, Shivayogappa $S$. \\ Teli $^{3}$, Krishnamurthy Soundariya ${ }^{3}$
}

${ }^{1}$ Assistant Professor, ${ }^{2}$ Associate Professor, ${ }^{3}$ Professor, Department of Physiology, Sri ManakulaVinayagar Medical College and Hospital, Kalitheerthalkuppam, Pondicherry, India

(Received: July 2020

Revised: February 2021

Accepted: March 2021)

Corresponding author: S. Mangani Mangalavalli. Email:manganimangalavalli@gmail.com

\begin{abstract}
Introduction and Aim: Prehypertension and obesity are the important cardio metabolic risk factors for developing metabolic syndrome. Neck circumference (NC) is an effective marker and screening tool for obesity. It gives a quick assessment of the upper body fat distribution. Early detection of obesity and prehypertension can increase the longevity of the individual. Hence, we aimed at evaluating the association of NC with prehypertension and obesity in young adults.
\end{abstract}

Materials and Methods: A cross sectional study where 150 Paramedical students were screened for prehypertension and fifty students were identified as pre-hypertensives $(n=50)$. Routine anthropometric measurements were taken. NC was measured. The correlation of NC with body mass index (BMI), systolic blood pressure (SBP) and diastolic blood pressure (DBP) was calculated. The prevalence and percentage distribution of obesity using NC in prehypertensive was calculated. The association of NC with obesity and prehypertension was demonstrated.

Results: The prevalence of obesity in prehypertensive students was $58 \%$. The distribution of obesity using NC was $61 \%$ in males and $55 \%$ in females. Further, the association of NC with BMI $(r=0.53, p=<0.0001)$, SBP $(r=0.52$, $\mathrm{p}=<0.0001)$ and DBP $(\mathrm{r}=0.44, \mathrm{p}=<0.0001)$ was calculated using Pearson's correlation and was statistically significant.

Conclusion: There was an increased prevalence of obesity among pre-hypertensives with a male predisposition. The study also establishes a statistically significant and strong correlation of NC with BMI, SBP and DBP. NC can be used as an effective screening tool to assess obesity and prehypertension.

Keywords: Body mass index; systolic blood pressure; diastolic blood pressure.

\section{INTRODUCTION}

I $t$ is a disconcerting revelation that the worldwide prevalence of obesity has actually tripled since 1975. Almost 39\% of adults under the age group of 18 and above were found to be overweight in the year, 2016 and almost $13 \%$ fell in the category of obesity. It was startling to note that over 38 million children who were under the age of 5 were found to be overweight or obese in the year 2019. It is quiet appalling to note the fact that in India almost 135 million individuals are obese. The prevalence of obesity according to an Indian Council of Medical Research-India Diabetes (ICMR-INDIAB) study done in 2015 was at a range from $11.8 \%$ to $31.3 \%$ (1). Obesity is said to be a condition of having excess body weight due to fat, causing ill health. In fact, obesity has become a disease of the modern era. In today's world a huge population resides in countries where obesity and overweight cause more mortality than underweight. It is noted that almost $5 \%$ of noncommunicable diseases in the world are strongly associated with overweight and obesity (2). According to the World health organization (WHO) statistics, nearly 3.2 million deaths are because of physical inactivity, which ultimately predisposes to obesity and overweight causing an inclination to develop non-communicable diseases like hypertension, cardiovascular disorders (3).

Prehypertension is also identified as an important risk factor for cardiovascular disease and is detrimental to the life expectancy by decreasing it by 5 years, as it is mostly, if not always develops into full blown hypertension, (almost half of the prehypertensive become hypertensive in about 4 years' time) (4). Hence it is quite necessary to monitor even a case of low risk prehypertensive individual annually. The Framingham study showed that if a person with prehypertension was not treated, then these patients more likely develop hypertension in future. Therefore, prehypertension is given a lot more importance both while screening and treating because the sooner it is identified and treated the better is the lifespan of the individual. Early detection of prehypertension by routine screening, keeping the Body mass index (BMI) on check by lifestyle modifications such as regular physical exercises and maintaining a healthy balanced diet, will help us to lead an active, healthy life (5). 
Studies showed that the main risk factors for developing prehypertension and eventually hypertension was overweight and obesity (6). Further evidence exists in proving the association of increased body fat to hypertension (7). Traditional techniques used in the assessment of central obesity are Waist circumference (WC), Hip circumference (HC), waist/hip ratio, mid arm circumference and Neck circumference (NC) (8). NC is considered as more accurate than BMI because its association is much stronger with central obesity than the BMI and it is also far more convenient and simple technique (9). NC may be considered as a vital parameter in assessing central adiposity and also visceral adiposity (10). It is also considered as an important independent indicator of risk for the metabolic conditions as per the Framingham heart study (11). It is used mainly to assess the upper body fat distribution and thence the obesity state of an individual (12). For routine screening purposes in health care settings, for research purposes wherein the use of expensive and sophisticated machines is neither easy nor justifiable, $\mathrm{NC}$ shall be adopted as a simple yet effective tool for screening. Moreover, in certain special circumstances as screening for obesity in pregnant women, $\mathrm{NC}$ might be considered as a meaningful method of assessment (10). Hence, this study was undertaken to use $\mathrm{NC}$ as a marker of obesity and to establish its correlation with BMI and prehypertension among prehypertensive young adults.

\section{MATERIALS AND METHODS}

The present study was undertaken at Sri Manakula Vinayagar Medical College and Hospital (SMVMCH), Pondicherry. It was a cross sectional study, wherein 150 paramedical students of both sex and of adult age group (18-25 years), belonging to partner institutions were screened for prehypertension based on Joint National Committee (JNC) criteria in which systolic blood pressure (SBP) of range 120-139 mm Hg and a diastolic blood pressure (DBP) of range $80-89 \mathrm{mmHg}$, were categorized as prehypertensive. After satisfying the inclusion criteria and obtaining their willingness to participate, they were taken up for the study $(n=50)$. Informed consent was obtained from all the participants. The protocol was approved duly by the Human Research Ethics committee. A complete medical history was elicited using a structured questionnaire and physical examination was performed. Participants with SBP $\geq 140 \mathrm{mmHg}$, DBP $\geq 90 \mathrm{mmHg}$, participants with existing thyroid disease or enlargement, any form of neck abnormalities and ill subjects were excluded from the study.

\section{Methodology and data collection}

Almost 150 Paramedical students belonging to our partner institutions were screened for elevated blood pressure and the students identified as prehypertensive $(n=50)$ according to JNC 7 criteria and were included in the study. Informed consent was obtained, and then relevant history was collected from the participants. The principal investigator measured the blood pressure. The subjects were made to sit comfortably in the department laboratory for 30 minutes, after which the blood pressure was measured in supine position by mercury sphygmomanometer, between $10 \mathrm{am}$ to $11 \mathrm{am}$. Three blood pressure readings were measured, and an average value was taken. Pre-hypertensives were diagnosed as per JNC 7 criteria, where the grey area between SBP of 120-139 mmHg and DBP of 80-89 $\mathrm{mmHg}$ is defined as "prehypertension." Routine Anthropometric measurements like height, weight, WC, were measured appropriately and thence the BMI was calculated accordingly. Height was measured to the nearest $0.1 \mathrm{~cm}$ asking the subject to stand in erect position with no shoes and feet kept flat on floor on a vertical scale, with the heels touching the wall and the head kept straight. Body weight was measured to the nearest $0.1 \mathrm{Kg}$ making sure that the subject was minimally clothed and without shoes, standing motionless on a weighing scale. Body Mass Index [QUETELET INDEX] BMI was calculated using the formula weight in kilograms divided by square of height in meters $(\mathrm{kg} / \mathrm{m} 2)$. NC was measured using a non-stretchable plastic measuring tape in the midway of the participants neck, (midcervical spine and mid anterior neck) while the subject is standing erect. In men, it was measured just below the laryngeal prominence - their Adam's apple to the nearest $0.1 \mathrm{~cm}(13)$. The standard NC cutoff in males was taken as $36.50 \mathrm{~cm}$ and in females was taken as $32.50 \mathrm{~cm}$ in people of Asian Indian origin. This screening test cut off value had a sensitivity of was $84.85 \%$ in males and $73.68 \%$ in females (14).

\section{Statistical analysis}

The data thus obtained was entered simultaneously in Microsoft Excel spreadsheet and subsequently the mean \pm standard deviation was calculated. The frequency distribution of obesity using $\mathrm{NC}$ among prehypertensive and the gender predisposition also was calculated using SPSS software version 16 . The association of NC with BMI, SBP and DBP was calculated using Pearson's correlation test.

\section{RESULTS}

Among the 50 prehypertensive young adults, $(n=50)$, 21 were male and 29 were female (table 1 ). In the 21 male prehypertensive participants, 8 were having normal standard NC and categorized as normal, nonobese and 13 were found to have increased NC and hence categorized as obese (table 1). Among the 29 
female prehypertensive participants, 13 had normal standard NC and were considered normal, non-obese whereas 16 had increased neck circumference and categorized as obese. Out of the net study participants $(n=50), 21$ participants i.e., $42 \%$ (both male and female) were found to have normal standard $\mathrm{NC}$ and categorized as normal and 29 participants i.e., 58\% had increased $\mathrm{NC}$ and were categorized as obese individuals (fig. 1).

Table 1: Prevalence of obesity (using neck circumference) among prehypertensives

\begin{tabular}{|c|c|c|}
\hline & Male & Female \\
\hline Normal & 8 & 13 \\
\hline Obese & 13 & 16 \\
\hline
\end{tabular}

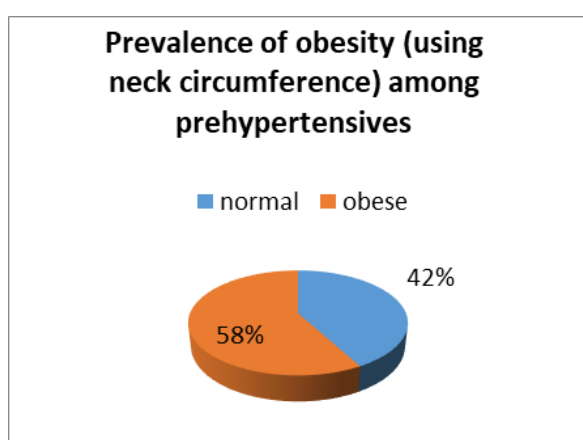

Fig. 1: Prevalence of obesity (using neck circumference) among Pre-hypertensives

Hence, the prevalence of obesity (using neck circumference) in prehypertensive young paramedical students was $58 \%$.

Table 2: Distribution of obesity among males and females

\begin{tabular}{|c|c|c|}
\hline & Male & Female \\
\hline Normal & $39 \%$ & $45 \%$ \\
\hline Obese & $61 \%$ & $55 \%$ \\
\hline
\end{tabular}

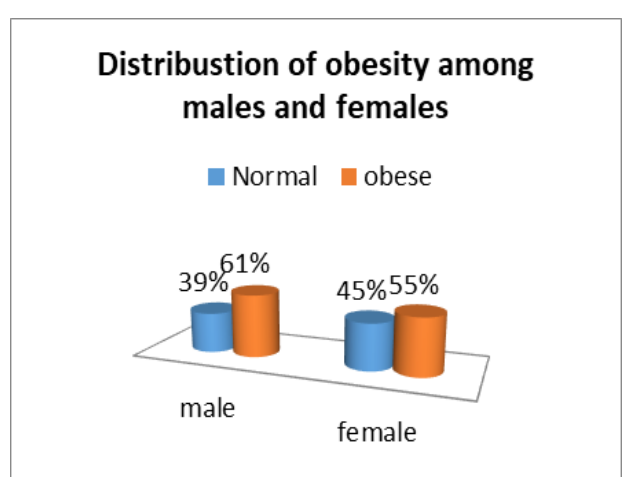

Fig. 2: Distribution of obesity among males and females

The distribution of overweight and obesity using NC was found to be $61 \%$ in prehypertensive young males and $55 \%$ in prehypertensive young females. $39 \%$ of prehypertensive males and $45 \%$ of prehypertensive females were found to have normal NC and were non obese (fig. 2).

Table 3: The Mean \pm Standard deviation of all the parameters assessed

\begin{tabular}{|c|c|c|}
\hline Parameters & Males & Females \\
\hline & Non-Obese & Obese \\
\hline BMI $\left(\mathrm{kg} / \mathrm{m}^{2}\right)$ & $21.4 \pm 2.63$ & $26.5 \pm 1.33$ \\
\hline SBP $(\mathrm{mmHg})$ & $124.76 \pm 2.38$ & $132.92 \pm 4.21$ \\
\hline DBP $(\mathrm{mmHg})$ & $82.5 \pm 0.93$ & $85.38 \pm 2.22$ \\
\hline
\end{tabular}

$\mathrm{p}$ value $<0.05$ was statistically significant

Table 4: Pearson's correlation of NC with BMI, SBP and DBP

\begin{tabular}{|c|c|c|}
\hline Parameters & \multicolumn{2}{|c|}{ Neck Circumference $(\mathrm{cms})$} \\
\hline & r value & p value \\
\hline BMI $\left(\mathrm{kg} / \mathrm{m}^{2}\right)$ & 0.53 & $<0.0001$ \\
\hline $\mathrm{SBP}(\mathrm{mmHg})$ & 0.52 & $<0.0001$ \\
\hline $\mathrm{DBP}(\mathrm{mmHg})$ & 0.44 & $<0.0001$ \\
\hline
\end{tabular}


$\mathrm{p}$ value $<0.05$ was statistically significant.

Thus, a strong positive correlation between $\mathrm{NC}$ and BMI, SBP and DBP was proved statistically (table 3 \& 4).

\section{DISCUSSION}

In the present study, it was reported that the prevalence of obesity (using NC) was around 58\% in young prehypertensive paramedical students. There was a gender predisposition in which the prevalence of obesity among males was $61 \%$ and that in females was $55 \%$, showing a higher prevalence among male prehypertensive adults. There was a statistically strong positive correlation existing between $\mathrm{NC}$ and BMI and prehypertension (SBP and DBP). To begin with this study, it was hypothesized that there is a strong association between NC with prehypertension and obesity. This hypothesis was proved to be true by our study. There was a significant association of increased $\mathrm{NC}$ with prehypertension indicating that $\mathrm{NC}$ can be a reliable marker and screening tool to assess obesity which can predispose to elevated blood pressures in young adults. It is observed that there is a statistically significant strong association of increased NC with prehypertension. Vague et al., were pioneers as early as 1956, in putting forth the concept of upper body fat distribution having a lot of clinical implications (15). Rajagopalan et al., and Yilmazel showed a significant association between high BP with increased NC and increase in BMI. The study also showed that obesity and overweight had a positive correlation with an increase in SBP and DBP $(16,17)$. Guo et al., (18) showed that the early identification of prehypertension can be improved by measuring the $\mathrm{NC}$ in normal weight children and also in adolescents more than their BMI. Kurtoglu et al., (19) demonstrated that there was a strong association of $\mathrm{NC}$ with blood pressure in a study on obese children in Turkey. Liang et al., demonstrated that increased $\mathrm{NC}$ measurements were directly associated with an increased the risk of prehypertension (20). The Framingham heart study had shown a strong association between NC and cardiovascular disease risk factors. Zhou et al., (11) had demonstrated in a cross-sectional study in which they showed that there was significant association of NC with SBP, DBP in both the genders. A lot of experimental studies established that a there is increased lipolysis when fat is more likely stored in the upper body (21). This increased lipolysis is related to an increase in release of free fatty acids, more endogenous production of very low density lipoprotein (VLDL) and glucose by the liver and insulin resistance (22). These significant changes ultimately lead to metabolic syndrome which is more obvious due to excess visceral and adipose tissue which is measured with the NC. Fox et al., demonstrated a significant relationship between metabolic risk factors and visceral adipose tissue
(23). Our study findings are further supported by Kuciene et al., where there was a good association of $\mathrm{NC}$ with high BP in children and adolescents (24). Hence this study demonstrates a statistically significant strong association of increased NC with prehypertension in young adults. However, there are a few limitations in our study, wherein the participant's lifestyle and diet information were not collected. The sample size was less, as this was a preliminary study which needs further exploration and research in future. Our conclusion of relating the prevalence of obesity, measured using NC with prehypertension may be extended to wider population in future.

\section{CONCLUSION}

Our study demonstrated a clear significant increase in the prevalence of obesity measured using $\mathrm{NC}$ among prehypertensive young adults. $\mathrm{NC}$ can be used as an effective screening tool to assess the upper body fat distribution and thereby assess the prevalence of obesity during screening purposes and demonstrates a statistically strong, positive association between NC with prehypertension, demonstrating the importance of identifying prehypertension, which is a precursor of hypertension, by a simple NC measurement. When obesity, overweight and prehypertension in young adults is picked up at an early stage, then lifestyle modifications, diet changes, routine physical activity can be incorporated for a healthier life, which might in fact help to prevent and/or manage prehypertension and in turn prevent the development of hypertension in future thereby increasing the longevity of the people.

\section{CONFLICT OF INTEREST}

There is no conflict of interest in this study.

\section{REFERENCES}

1. Ahirwar, R., Mondal, P. R. Prevalence of obesity in India: A systematic review. Diabetes MetabSyndr. 2019; 13(1): 318321.

2. Alwan, A. Global status report on non communicable diseases 2010 Geneva, Switzerland. World Health Organization; 2011.

3. Kumanyika, S., Jeffery, R. W., Morabia, A., Ritenbaugh, C., Antipatis, V. J. Public health approaches to the prevention of obesity (PHAPO) working group of the international obesity task obesity prevention: The case for action. Int J ObesRelatMetabDisord.2002; 26: 425-436.

4. Joseph, La Dou., John, R., Neal, L., Paul, D., Mahbub, M. V., Jennifer, H. Current occupational and environmental medicine. 3rd edi. Mc Graw Hill. 2004; 603-618.

5. Mangalavalli, M., Bethiun, N., Senthilvelou, M., Shivayogappa, T., Soundariya, K. Does your personality make you fat!!! A study on young prehypertensives. IJBAMR. 2015; 4(3): 195-203.

6. Laura, P., Svetkey. Management of hypertension. Hypertension. 2005; 45: 1056-1061.

7. Bao, W., Threefoot, S. A., Srinivasan, S. R., Berenson, G. S. Essential hypertension predicted by tracking of elevated blood pressure from childhood to adulthood: the Bogalusa Heart Study. Am J Hypertens. 1995; 8(7): 657-665. 
8. Hatipoğlu, N., Mazıcıoğlu, M., Kurtoğlu Kendirci, M. An additional tool of screening overweight and obesity in childhood. Eur J Pediatr 2010,169: 733-739.

9. http://www.emaxhealth.com/1506/neckcircumference-mostreliable-alternative-bmichildhood-obesity.

10. Joshipura, K., Muñoz-Torres, F., Vergara, J., Palacios, C., Pérez, C. M. Neck. Circumference may be a better alternative to standard anthropometric measures. Journal of Diabetes Research. 2016; 8.

11. Zhou, J. Y., Ge, H., Zhu, M. F., Wang, L. J., Chen, L., Tan, Y. Z., et al., Neck circumference as an independent predictive contributor to cardio-metabolic syndrome. Cardiovascular Diabetology, 2013; 12: 76-78.

12. Ben-Noun, L., Sohar, E., Laor, A. Neck circumference as a simple screening measure for identifying overweight and obese patient. Obesity Research. 2001; 9(8): 470-477.

13. Ben-Noun, L, Laor, A. Relationship between changes in neck circumference and cardiovascular risk factors. Exp Clin Cardiol. 2006; 11(1): 14-20.

14. Patil, C., Deshmukh, J., Yadav, S., Patil, S., Sheikh, A. Neck circumference: A novel anthropometric tool for screening obesity in adults. IJCRIMPH. 2017; 9(7): 711720.

15. Vague, J. The degree of masculine differentiation of obesities: a factor determining predisposition to diabetes, atherosclerosis, gout, and uric calculous disease. Am J Clin Nutr. 1956; 4(1): 20-34.

16. Rajagopalan, A., Balaji, N. Association of neck circumference and obesity with blood pressure among adolescents in urban and rural population in North Tamil Nadu. J Nat Sci Biol Med. 2017; 8(2): 144-149.

17. Yilmazel, G. Prehypertension prevalence and its association with neck and abdominal obesity in disease-free young adults. Acta Medica Mediterranea. 2017; 33(2): 329-334.

18. Guo, X., Li, Y., Sun, G., Yang, Y., Zheng, L., Zhang, X., et al., Prehypertension in children and adolescents: association with body weight and neck circumference. Intern Med. 2012; 51: 23-27.

19. Kurtoglu, S., Hatipoglu, N., Mazicioglu, M. M., Kondolot, M. Neck circumference as a novel parameter to determine metabolic risk factors in obese children. Eur $\mathrm{J}$ Clin Invest. 2012; 42: 623-630.

20. Liang, J., Wang, Y., Dou, L., Li, H., Liu,X., Qiu, Q., et al., Neck circumference and prehypertension: the cardiometabolic risk in Chinese study. J Hypertens. 2015; 33(2): 275-278.

21. Sjöström, C. D., Håkangård, A. C., Lissner, L., Sjöström, L. Body compartment and subcutaneous adipose tissue distribution: risk factor patterns in obese subjects. Obes Res. 1995; 3(1): 9-22.

22. Nielsen, S., Guo, Z., Johnson, C. M., Hensrud, D. D., Jensen, M. D. Splanchnic lipolysis in human obesity. J Clin Invest. 2004; 113(11): 1582-1588.

23. Fox, C. S., Massaro, J. M., Hoffmann, U., Pou, K. M., Maurovich-Horvat, P., Liu, C. Y., et al., Abdominal visceral and subcutaneous adipose tissue compartments: association with metabolic risk factors in the Framingham Heart Study. Circulation. 2007; 116(1): 39-48.

24. Kuciene, R., Dulskiene, V., Medzioniene, J. Association of neck circumference and high blood pressure in children and adolescents: A case-control study. BMC Pediatr. 2015; 15: 127. 